\title{
Research on Construction Management of Precast Beam of Highway Bridge Engineering
}

\author{
Xu Bin \\ Kunming College, Kunming, China, 650214
}

Keywords: prefabricated beams; engineering; management

\begin{abstract}
In China, precast beams play a vital role in the construction of highway bridge.in order to give them full play, it is necessary to improve the relevant technology, the precast beam field location principle analysis, improve the technology and construction as well as the quality of management.

Now, highway and bridge construction enterprises in China have been developing at a high speed, and have been accelerating continuous adjustment. They have adapted to the development of the market and achieved objective economic benefits. However, there are some problems in the construction of roads and bridges in China, and there are loopholes in the management. Therefore, managers of the enterprise should improve the management of the project and continuously increase the economic benefit of the enterprise [1].
\end{abstract}

\section{The principle and arrangement principle of prefabricated beam field location}

Precast beam is completed after centralized prefabrication, mainly through the way of erection to complete various construction activities. The weight of precast beam is very large, so we need to use centralized prefabrication. In order to improve the design of precast beam field, the position of prefabricated beam should be determined first, so as to ensure the smooth construction of the beam. In designing precast beam, we should follow certain principles. First, we need to make an in-depth analysis of the size of the site. The site of the precast beam yard should meet the corresponding needs, combined with the environment of the site. Secondly, the choice of transportation equipment should be very reasonable. Only the above two conditions can be satisfied, the precast beam field can be reasonably built to ensure the normal operation of the precast beam field. As the size of the precast beam is very large, a large amount of space is needed on the basis of a large number of transportation, so as to ensure the smooth transportation and storage. In the link of transporting prefabricated beams, the appropriate transportation distance should be determined, thus effectively shortening the intensity of transportation and reducing the cost of transportation. The prefabricated beam field should be arranged in a reasonable position, and the main position distribution has the way of transverse distribution, longitudinal distribution and double layer beam storage.

\section{Related construction technology}

During the application of $\mathrm{T}$ beam, the steel plate must be fixed. Before the installation, the template should be cleaned up to prevent the installation of the steel plate with foreign objects, and the template should be brushed with the isolating agent to ensure the correct linearity of the template. In the seam treatment of the template, it is necessary to ensure a good combination and the use of latex paste to prevent the production of leakage. The removal is completed, if there is some damage should be two times of sponge paste. Should consider whether the template is convenient to disassemble, each section of the template after the demolition will form a live template in the template removal process, you should first and then remove the bolt, the trap of each phase, to prevent the degeneration of the situation [2].

Complete steel processing in the processing plant, installed on the girder pedestal, should be designed with steel horseshoe, the number of tie bars is very dense, so the location is very easy to 
change, so can the pedestal side marking positioning way, which can accurately find the root number and spacing, transverse the partition in the steel after the completion of the construction, installation and then bundled steel bars to maintain a certain distance, the general distance control in 0.8 meters. Because corrugated pipelines are made up of curves, it is very important to determine the location of each bar. In construction, we must use the way of ruler calibration and determine the location coordinates of the corrugated residence according to the coordinates of the design drawings. The coordinates directly carved in wood square rod, with the rod position determine the location rib, by way of welding fixed position bar, so as to ensure the positioning rib in a steady state. The template is located, to start the installation of flange reinforced, finally completed the strapping operation. In order to ensure that the protective layer of the steel bar has a certain thickness, after the reinforcement skeleton is formed, the distance between the reinforcing bars should be well controlled, the spacing of the blocks should be controlled in the form of cushion blocks, and then be bundled in plum blossom pattern according to the design requirements. After the steel bar is tied up in the web, it should be inserted in the order of the bellows, fixed the positioning tendons, and bundled the electrical rubber cloth [3].

In order to improve the pouring quality of a large number of concrete, we should pay much attention to the purchase and purchase of concrete. $T$ beams are generally used in horizontal layering, and the thickness of each layer is generally not more than 30 centimeters. The pouring order is pouring out of the steel horseshoe, followed by the web, and finally the flange. In the links of concrete transportation, the concrete is directly pumped into the mold, and the inclination angle is 45 degrees for pouring. First, the two ends are poured. Finally, the pouring is carried out in the middle, so as to achieve continuous casting and ensure one molding. The width of $\mathrm{T}$ beam web is small, and the width of the bottom hoof is very large. Therefore, in the links of horseshoe vibration, we should improve the construction plan. Usually, we use vibrator to combine the attached vibrator and the plug-in vibrator together. To improve the vibration technology, the lower part of the bellows should be attached to the vibrator. In the aspect of Duanzhen beam pounding, you should add an attached type vibrator, so as to ensure the concrete vibrating compaction.

\section{Precast beam construction technology}

In the construction process, precast box girder should first bind the steel bar, then realize the piercing and piercing of the bellows, then install the core mold, and finally do the concrete placement.

In the process of making the template, the template should be divided into the bottom die, the outer die and the end die. The thickness of the bottom die is usually 6 millimeters, directly fixed in the buried channel steel, and then fixed by the back arch. The stiffness of the outer template should be very large in the installation of the outer membrane, and the whole side template should be connected to the bottom mould in the form of bolted connection at the construction site in a supporting design way. In the installation of endometrium, two small steel plates should be installed together. In order to facilitate the demolition of the template, wedge splicing should be used in the template splicing, so that the intima can be deformed under external pressure, and sunroof should be installed in the intima. The daily production of box girder is 8 , and the turnover cycle of the template is three days [4].

In the process of template installation, we should check the size of the template, analyze whether the template is smooth, and ensure the smoothness of the template. If there is any uneven condition, it cannot be installed. Remove the foreign objects on the template and use the vibration inspection method to weld the cracked template in time. Check the hoist and wire rope and analyze the integrity of the connector.

In the end the installation mode in the link, in the side of the mold after the installation is complete, you can end formwork installation, before installation should first identify the mode to ensure the end of line, line and die at the end of the line of coincidence, ensure that the beam height can meet the requirements of the position of the bellows to ensure accuracy. At the bottom of the end die, bolts should be used. 
In the link of the side mold installation, the binding of the steel bar in the bottom web should be fastened to ensure the accuracy of the coordinate of the bellows. In the side mode installation, start from one end, and then install on the other side after a section of the installation is completed. In the part of the side mold installation, we should pay attention to the width of the bridge deck and the thickening port. In the first part of the side mold, to ensure that the jack in place, the side mold edge is tightly connected with the bottom mold. In the construction process, should be combined with precast beam models to determine good embedded parts installation.

During the installation of the endocardium, after the installation of the lateral die is completed, the installation of the internal die is carried out after the acceptance is qualified. During the installation process, we should pre assemble and use bolted connections.

\section{Reinforcement engineering}

In the process of rebar processing, it is necessary to verify the content of the material report sheet to ensure that there is no difference between the material and the material. During the process of reinforcing steel bar, the surface and stains of steel must be cleaned in time. If the steel bar is granular, it can't be put into use. There is no cross section scar in the process of reinforcing steel bar. The steel should be in a flat state, and no bending should be made. The welding of steel bar is used in the way of butt welding, by hand arc welding. In the link of reinforcing steel bar, the joint of steel bar adopts the way of flash butt. In the application of this process, the diameter of the steel bar is relatively small, and the continuous flash welding method is adopted. If the diameter of the steel bar is very large and the evenness of the port is better, the preheating flash welding can be used. If the port of steel is rough, the preheating flash welding should be used. Before the steel is welded, the relevant parameters should be perfected to ensure the qualification of the parameters and then batch welding. In accordance with the actual conditions, the advanced nature of the test welding, and then batch welding [5].

In the link of reinforcement binding, we should analyze the relationship between the bottom of the box girder, the reinforcement of the web and the reinforcement of the panel, and then carry out the binding between the internal die and the side die reinforcement after the reinforcement is finished. In the link of reinforcing bar binding, it is necessary to ensure that the intersection point of steel bar is clear, and the error can not be too large in the link of the beam in the binding. In the binding, the bending degree should be well controlled, and the position of the junction point should be tied firmly. In the link of the binding, the longitudinal cross arrangement should be perfected. Lashing wire should be used in the way to increase the protective layer.

In the application of steel bar positioning mold, in order to improve the binding speed of precast beam and improve the acceptance rate of a check, the way of reinforcing bar positioning should be adopted in the reinforcement of the precast beam.

Prepreprestressing of prestress pass should be used in the way of plastic bellows, combined with positioning network for construction. The plastic bellows should be laid out according to the coordinates of the pipeline in the layout, and the location reinforcement should be set up, and the corrugated pipe should be fixed to the reinforcement. Positioning network welding should be very reliable, in the placement of the link, can not produce any movement. In the prestressing tendons, the accuracy of the size and position should be ensured, thus forming the center line of the pass. In the links of plastic corrugated pipe welding, we must enhance its airtightness and prevent the leakage of cement mortar. We should use vacuum pumping to enhance its strength and prevent damage during transportation and pouring. The flexibility of the pipe should be guaranteed to prevent wear.

\section{Measures for quality control of construction}

In the test of prestressed tendons, analyzes its elongation and elastic modulus, if the raw material is not qualified, not into the construction, the prestressing mechanical test, to determine a good measurement standard, to improve the pump jack and other oil spill maintenance. The prestress 
operators should be trained to improve their business ability and improve their ability to use the equipment.

In the concrete configuration, the content of chloride ion in concrete should be analyzed to prevent the content of chlorine ion too high and to improve the operation of mixing and pressing. If the water quality is not good, we should prevent aggregate reaction, and if the content of alkaline oxide in cement is very large, we should use silicic acid gel to reduce the production of reaction. If there is a serious problem of water absorption in the raw material, the cement will be damaged, and the content of the alkaline substance in the cement should be reduced. The content of silica in the material used is less than $1 \%$. Test the large mixing station on a regular basis, so as to analyze the accuracy of the measurement [6].

The exact location of prestressed reinforcement is directly related to the application of each section of $\mathrm{T}$ beam. Therefore, in the construction process, we should analyze the reasons for the change of the location of prestressed reinforcement. In the links of engineering management, we should check every coordinate point of prestressed reinforcement, and ensure that the supervisors take effective measures to fix the prestressed tendon and prevent the movement from happening in the construction.

\section{Common preventive measures for quality problems}

In the process of vibration, we should follow the method of tight insertion and slow pulling, and if the surface of concrete appears flat and wide, then we can stop the vibration. The slanting mouth of a horse's hoof should be well controlled, so as to help exhaust, and it is difficult to vibrate. It's necessary to use attached vibrator and artificial vibration. In the slant construction of the hoofs on the hoofs, the height of the concrete layer should be combined. The nature of the mixing of concrete admixtures should be combined, in the initial vibration in the link, if concrete is placed too long, it will cause the water to cement ratio change, then should re cement stirring, in the dust discharge process, should remove lump. If the concrete is very serious, stop using it.

The beam and horseshoe should use an attached vibrator to prevent the occurrence of harden in the link of concrete pouring. In concrete pouring, it should be sprinkled in time to prevent the formation of solidification. But it can not produce water. Before pouring, the stitching of the template should be checked and the seams of the leaky slurry are remedied in a timely manner. The performance of the template should be very clean, and the isolation layer should be evenly brushed.

Before pouring, the stitching of the template should be analyzed and watered. In the casting process, the quality of the template should be checked, and the time of vibration should be strictly controlled. In control of slump, the strength should be enhanced by adding cement. In the selection of vibrating tools, the working degree of concrete should be ensured.

\section{Conclusions}

With the rapid development of social economy and science and technology, people's living standards have been steadily improved, and people have put forward higher requirements for highway bridges. In the highway bridge construction process, construction management of precast beam is very important, not only can improve the overall quality of the bridge project, but also can improve the management of the construction, is the key to the overall quality of the construction project of our country should enhance the construction of full attention in bridge engineering, aiming at the problems in construction, improvement the proposal. In the specific construction links, we should coordinate the construction management of precast beams, control the cost of market construction and construction, so as to meet individual needs and show the characteristics of the whole project.

\section{References}

[1] Hai M, Liu L. Discussion and Practice of the Precast Beam Construction Management in 
Highway and Bridge Construction [J]. Urbanism \& Architecture, 2014.

[2] Wu C. Management Strategy for Highway Engineering Precast Girder Construction [J]. Science \& Technology \& Innovation, 2015.

[3] Kim Y S. Precast and bracket construction method of T-beam and PC-beam bridge without staging[C]// International Road Federation World Meeting, 11th, 1989, Seoul, Korea. 1989.

[4] Bennion C. Temporary Works Toolkit: Part 11: Temporary works associated with precast concrete bridge beam construction [J]. Structural Engineer Journal of the Institution of Structural Engineer, 2017, 95: págs. 37-41.

[5] Sack R L. AN INVESTIGATION OF PRECAST AND PRESTRESSED CONCRETE BULB TEE MULTI-BEAM BRIDGES [J]. Journal of Biological Chemistry, 1975, 287(26):21699-716.

[6] Buth E, Furr H L, Jones H L, et al. USE OF PRESTRESSED, PRECAST CONCRETE PANELS IN HIGHWAY BRIDGE CONSTRUCTION[J]. Transportation Research Board Special Report, 1974. 